\title{
The Biology of Moult in Birds
}

By Lukas Jenni and Raffael Winkler. 2020. Helm. 320 pages and 151 illustrations, 76.50 USD, Cloth, PDF E-book, or EPUB/ MOBI E-book.

Every bird does it ... replaces all of its feathers, that is, usually once a year for smaller birds and longer for larger birds. The process of doing so is called "moult". There are two main reasons this is done: (1) worn, damaged, or lost feathers must be replaced to maintain plumage function, such as insula-

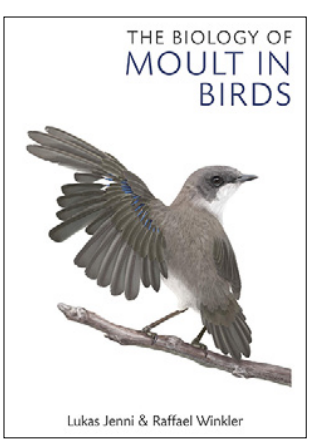
tion and flight, and (2) feathers are replaced to adjust to changing requirements, such as the need for colourful plumage to attract mates. This sounds simple but is anything but. For instance, a hummingbird has some 1000 contour (body) feathers, and a swan has 25000 ! And, with the exception of most waterfowl and a few other species, a bird still needs to fly while moulting its wing feathers. Fitting moult into a bird's annual cycle of breeding and migration (for temperate-breeding species) usually requires tradeoffs, some at the behavioural level and others at the physiological level. While there is usually some overlap of moult with breeding and/or migration, Common Murre (Uria aalge) overlaps all three life history stages by feeding its chicks at sea, while migrating by swimming because it has simultaneously moulted all of its flight feathers. Talk about multi-tasking! A behavioural example is that of Rock Ptarmigan (Lagopus muta), which moults its plumage to match its Arctic environment; however, the male keeps his white winter plumage longer than the female does to attract mates, then when the female starts laying eggs he purposely soils his plumage to be more cryptic until he moults into his brown summer plumage.

The Biology of Moult in Birds is a textbook on the what, why, where, when, and how of moult, with some fascinating examples such as the two above. The book is organised into five chapters: (1) functions of plumage, (2) plumage maintenance and need for renewal, (3) processes of moult, such as feather growth and physiology, (4) effects of environmental conditions during moult on plumage quality, and (5) moult strategies, or fitting moult into the annual cycle. Each chapter is divided into sub-sections, each of which has a plain language summary, plus a summary and concluding remarks at the end of the chapter. The text is superbly complemented by 151 figures, all with clear and informative captions. Many of the figures include multiple photographs, from microscopic detail of feathers to stages of moult in different species, and the coloured illustrations include a variety of styles of graphs, 3-D drawings, and flow charts. Most of the examples, whether in the text or the figures, are of European species, which reflects where Jenni and Winkler are based, but also where much of the research on moult has been undertaken. However, it is reasonably easy to think of a similar species in North America. I confess to skimming over some of the details, such as those on physiology, but felt that I understood the basics by reading the summaries and studying the figures. The book ends with 41 pages of small-print references and an 18page detailed index.

The onset, duration, extent, and speed of moult at the individual level are governed largely by a genetically determined (innate) schedule, which interacts with day length (photoperiod), and is modified by breeding activity and social cues (e.g., number of nestlings, parental care), and environmental factors such as food availability, temperature, and parasite load. At the species level, moult is governed by the size and morphology of the bird, its lifestyle, and annual cycle needs. It is common to read about the "costs" of moult: reduced insulation may require more fuel to maintain 
metabolic functions, flight costs increase when there are gaps in the flight feathers, hunting success is reduced for raptors, reluctance to fly may increase predation risk. However, I was surprised to read that some of these costs may be compensated for by changing the wingbeat to maintain flight, adapting the resting metabolic rate, and reducing body weight yet increasing muscle mass. And these costs may actually be less than during the breeding season, when birds are laying eggs, feeding young, and defending territories.

I found the final chapter, on fitting moult into the annual cycle, the most interesting. As a bird bander, an understanding of a species' moult strategy - the timing, place, extent, speed, and sequence of moult - is critical to being able to determine the age of a bird, a key demographic parameter in scientific studies. Moult strategy is determined by (1) the length of the longest primaries, which impacts the time required to grow new ones, (2) the degree of flight capability needed during moult, (3) the timing of breeding and/or migration, and (4) the ease of obtaining food during moult.
Moult studies have been difficult to undertake, but the authors have done a good job of synthesizing the data. Most were undertaken with captive birds, which raises the question of how representative these are of free-living birds. There have not been as many studies on large birds, such as raptors or herons, because they are difficult to keep in captivity. As a result, there is still a lack of studies on many aspects of moult, and the section summaries often raise questions for which more research is required. As Jenni and Winkler state in their concluding remarks:

Many studies of annual cycles by default give a premium role to reproduction and migration, rather than moult. However, while breeding can be skipped, moult is a life-history stage essential for survival by maintaining flight and feather function. (p. 238)

It is a fascinating topic.

Cyndi M. Smith Canmore, AB, Canada

(C) The author. This work is freely available under the Creative Commons Attribution 4.0 International license (CC BY 4.0). 